\title{
An Exploration of Language-Based Multiplicity in Fluent Bilinguals
}

\author{
Johanna Tiemann \\ Private Practice
}

\begin{abstract}
This study used projective tests to explore the language-based shifts in aspects of personality observed in fluent bilinguals. The Rorschach Comprehensive System (RCS) and the Thematic Apperception Test (TAT) were administered in Spanish and in English to 26 fluent Spanish/English bilinguals, and protocols were compared based on measures of affect, self-perception, cognitive complexity, and object relations. No significant differences were found between language protocols for most measures, nor did these measures relate to age of second language learning, relative use of English and Spanish, or participation in therapy. However, cognitive effort was significantly greater on English RCS protocols, and a strong correlation between level of acculturation and freedom of expression in English was found. Further exploration of the data revealed very important differences between most subjects' Spanish and English protocols. Most notably, in 73\% of the cases, RCS protocols differed so extensively by language that different key variable for cluster interpretation and diagnosis were indicated, and $42 \%$ of subjects' modes of decision making (EB style) varied according to language. These findings are remarkable because these key variables are believed to measure constant, dominant and trait-like features of an individual's psychology. The findings underscored the need for norms based on this population, and development of culturally-based constructs for interpretation of the RCS.
\end{abstract}

\section{Introduction}

In the past century, a good deal of investigation has been made into the role of language in clinical work with bilinguals. One of the most intriguing aspects of this inquiry focuses on how the fluent bilingual's languages, and the particular cultural origins implicit to them, create and function as discrete contexts for experience. Exploration within the diverse fields of psychoanalysis, psychology, linguistics and anthropology has generated compelling evidence that language, as it is used to express and organize experience, asserts a salient influence on emotional experience, cognition, and the perception of the self, others, and one's environment. From this perspective, language may be regarded as a

1 Correspondence concerning this article should be addressed to Johanna Tiemann, 215 West 90th, \#4F, New York, NY 10024. E-mail: johannamt@nyc.rr.com 
lens through which the world and the self are perceived and known. If this is true, then language also has a fundamental influence on the development and expression of personality, and we may assume that bilinguals experience and convey multiple aspects of personality that are influenced by language.

In fact, the literature on bilingualism is replete with reports by bilinguals of their subjective experience of language-based aspects of personality (Amati-Mehler, Arentieri, \& Canestri, 1993; Ben-Rafael, 2004; Dewaele, 2004a; 2004b; 2004c; Hoffman, 1989; McMahill, 2001; Kaplan, 1993; Panayiotou, 2004a; Pavlenko, 1998, 2002a, 2000b; 2008). For example, in his interviews with bilinguals, Grosjean (1982) recorded several conversations with bilinguals who said they were aware of presenting themselves differently in their two languages. One man said that he perceived himself to be relatively aggressive or caustic when speaking his native language; and a woman said she felt she was polite and relaxed when speaking her second language, but anxious and rude in her first. Unsolicited accounts from sources outside the field also attest to this bilingual experience. Multilingual author, Natasha Lvovich (1997), writes about how she used her knowledge of French to "transcend the conditions of her Soviet life, to create a fantasy, to join an exclusive club" (p. ix). Sante, a French/English bilingual author stated compellingly in a New York Times article (Sante, 1996):

The first thing you have to understand about my childhood is that it mostly took place in another language. I was raised speaking French...This fact inevitably affects my recall and evocation of my childhood, since I am writing and primarily thinking in English. There are states of mind, even people and events, that seem inaccessible in English, since they are defined by the character of the language through which I perceived them. My second language has turned out to be my principal tool, my means for making a living, and it lies close to the core of my self-definition. My first language, however, is coiled underneath, governing a more primal realm.

French is a pipeline to my infant self, to its unguarded emotions and even to its preserved sensory impressions. I can, for example, use language as a measure of pain. If I stub my toe, I may profanely exclaim, in English, "Jesus!” But in agony, like when I am passing a kidney stone, I become uncharacteristically reverent, which is only 
possible for me in French. "Petit Jesus!" I will cry, in the tones of nursery

religion...but French is also capable of summoning up a world of lost pleasures.

Findings from the linguistic study of bilinguals and their languages have offered explanations for these varying language-based experiences. Cross-linguistic differences in emotion concepts ${ }^{2}$ (Pavlenko, 2008) have been found to include varying causal antecedents, appraisals, physiological reactions, and consequences and means of emotion regulation and display. For example, emotion can be seen as generated by internal organs (causal antecedents), (Heelas, 1983). Various kinds of emotion will evoke culture-bound judgments, for example, Westerners look down upon people who overtly express dependence, while this expression might be seen as positive by the Japanese (appraisals) (Doi, 1973; Morsbach and Tyler, 1986). When a Greek speaker experiences, stenahoria (discomfort/sadness) he/she often also experiences a feeling of suffocation, while English speakers do not tend to associate suffocation with discomfort/sadness (physiological reactions) (Panayiotou, 2004a). Expressions of anger are frowned upon in some cultures, but in others are seen as a show of healthy self-assertion (consequences and means of emotion regulation and display). These language and culture-bound emotion concepts surely impact the speaker's sense of self, and engenders an experience of context and language dependent multiple selves Panayiotou, (2004b). Pavlenko (2008) also points to the nonequivalence of conceptual categories for emotion words between languages that make translation of certain emotional experiences difficult or even impossible. To illustrate, the English concept of frustration, (Koreneva, 2003, p. 383, Panayiotou, 2004a), the Greek concept of stenahoria (discomfort/sadness/suffocation), (Panayiotou, 2004a), and the Japanese concept akogare (Japanese women's desire for the Western lifestyle and Western men) (Piller \& Takahashi, 2006) bear no counterparts in other languages. However, socialization in a second language allows for understanding of new concepts over time. Pavlenko (2008) proposes a 7-phase model that describes the speaker's progression from having no appropriate representation new emotion concepts in a second language through full integration of new concepts, and eventually to attrition of old native language concepts. She also posits a co-existence of emotion concepts in bicultural bilinguals. If this is true, then certainly a bilingual person's emotional experience in each language will vary, and will be directly correlated with the degree of fluency in each language.

Both Rintell and Pavlenko have explored the role of language in the interpretation of emotional cues. Using tape recorded conversations in English as stimuli, Rintell (1984) asked non-English speaking foreign students enrolled in an intensive English program to

2 Emotion concepts are "prototypical scripts that are formed as a result of repeated experiences and involve causal antecedents, appraisals, physiological reactions, consequences, and means of regulation and display. [They] are embedded within larger systems of beliefs about psychological and social processes, often viewed as cognitive models, folk theories of mind, or ethnopsychologies" (Russell, 1991, as quoted in Pavlenko, 2008, p. 150). 
describe the emotion expressed in the conversations. When these students' responses were compared with native English speakers' responses, Rintell found that the foreign students' assessments were mediated by linguistic background and cultural background, but the most significant effect was found for language proficiency. Her findings that even proficient speakers had difficulty with the task, and that speakers of certain languages had significantly more trouble identifying the emotions leads to the conclusion that the interpretation of emotions varies across cultures, contexts, emotion categories, and individuals, as well as across languages. With monolingual and bilingual Russian and English speakers as subjects, Pavlenko (2002a) employed a film with no dialogue as stimulus in a cross-linguistic study of the conceptual domains of private and personal. She found that the monolingual speakers differed significantly in their conceptualizations of the film, with high intra-group consistency. In contrast, bilinguals were more similar to the English monolinguals, but their recognition of concepts of private and personal was positively correlated with their proficiency in English. A bilingual's sense of having multiple self states therefore is also underpinned by the cultural aspects embedded in their two languages, and again is mediated by proficiency.

Clinicians who work with bilinguals have written extensively about their experiences with language-based aspects of their patient's personalities. In the mid $20^{\text {th }}$ century, Buxbaum (1949), Greenson (1950), and Krapf (1955) described the role of language in the psychoanalysis of bilinguals, noting differences in emotional expression, defense mechanisms, self-perception, recall of early memories, and transference based on the language of the treatment. They theorized that language could be co-opted by defensive processes, acting as a mechanism for isolating or splitting off features of personality. This idea that language can segregate aspects of cognitive and emotional functioning, rendered in the language of various psychological and psychoanalytic orientations, has been supported and elaborated by many authors over the ensuing decades. For example, Del Castillo (1970) described several bilingual patients whose psychotic symptoms were only apparent in their first language, and Malawista (2002) reported a case where conversion symptoms occurred in an analysis performed in the patient's second language. Javier (1995) reported that bilinguals' verbalizations differed in richness and detail as they recalled memories in one language or the other. The heightened emotional potency of narrative produced in the native language in therapeutic settings has been observed by many clinicians (for example, Marcos, 1988; Marcos \& Alpert 1976; Marcos \& Urcuyo 1979; Rozensky \& Gomez 1983) and the relationship between language choice and the quality of transference, defensive reactions, and self-experience has been described extensively (Antinucci-Mark 1990; Clauss, 1998; Kitron 1992; Lijtmaer, 1999; Marcos, Eisma, \& Guimon (1977); Amati-Mehler, Argentieri, \& Canestri, 1993; Mohavedi 1996; Perez Foster 1992, 1996, 1998).

Studies that have looked at emotion and native language have found empirical support for observations of the analysts cited above who found their bilingual patients' native language to be spoken more "from the heart." Drawing from findings that emotion words are recalled more easily in memory tasks (Rubin \& Friendly, 1986), Anooshian and Hertel (1994) found that bilingual speakers recall significantly more emotion words than neutral words in their first language, but remember the same number of emotion and neutral words in their second language. Harris, Aycicegi and Gleason (2003), found that 
when used as a measure of physiological reactivity to taboo words and childhood reprimands (e.g. "Shame on you!"), skin conductance responses (SCRs) were slightly higher in the bilinguals' first language. Those who learned the second language early and balanced bilinguals showed comparable SCRs in Spanish and English. Age of acquisition of the second language seems to be a strong predictor, with subjects who learned their second language after puberty showing greater strength of emotion expressed in the first language (Amati-Mehler, Argentieri \& Canestri, 1993; Bond \& Lai, 1986, Pavlenko, 2002b).

Contemporary psychoanalytic authors (Bromberg, 1996; Davies, 1999; Stern, 2003; Chefetz \& Bromberg, 2004; Stern, 2004) have developed and expounded upon the concept of multiplicity, positing that the compartmentalization of experience through dissociation is part of being human. Analytic authors who concern themselves with different experiences of self that are tied to multiple languages (Perez Foster 1992, 1996, 1998; Hill, 2008) have speculated that dissociation also plays a significant role in these experiences of multiplicity. However, the concept of language as an organizer of experience is not new to the field of anthropology; in fact, it is regarded as axiomatic. Contemporary anthropologists regard the assumption of a stable, bounded, coherent sense of self as an ethnocentric "folk model" reflective of our western emphasis on individualism (Geertz, 1984; Lutz, 1988; Abu-Lughod \& Lutz, 1990). These theorists posit that selves are fluid systems that provide an experience of wholeness through clearly defined, contextualized self representations. These self representations are largely discernible through dialogue, in which a sense of the experience of wholeness within the individual can be observed. Not only is dialogue regarded by these anthropologists as a means for studying shifts in self representations, but language itself is viewed as both a cause and effect of self experience (Ochs \& Capps, 1996). Narrative has also been thought to reflect affective responses that are characteristic of the culture in which the language is learned (Goddard, 1991; Lutz, 1988; Rosaldo, 1984; Wierzbicka, 1992). These findings have been validated by qualitative interpretation of projective tests (Ervin, 1964; Ervin-Tripp, 1968).

Although language is a primary tool in the assessment of cognitive, perceptual, and affective functioning, there is little research that explores how the perspective on language as an experiential context relates to the psychological assessment of bilinguals. Given the clinical evidence, we are left to wonder if our assessment tools can detect and confirm such language-based multiplicity, and if so, whether we are missing something by performing assessments on bilingual people in only one of their languages. The present study attempted to address this dearth of research by using the Rorschach Comprehensive System (RCS) and the Thematic Apperception Test in a repeated measures design to explore how language creates discrete personal contexts for the bilingual. Several hypotheses were developed and questions posed about how protocols might vary by language (see Tables 1 and 2). It was expected that RCS protocols administered to fluent bilinguals in their native tongue would indicate greater emotional and cognitive engagement and complexity than those administered in their second language. Statements made by clinicians regarding language-based shifts in transference 
led to the expectation that TAT protocols would indicate a language-based variance in the quality of object relations.

In addition, an attempt was made to identify some variables that moderate these language-based shifts. Since most of the relevant clinical literature is based on work with patients, it was hypothesized that factors that lead to seeking therapy, or the therapy experience itself, related in some way to these shifts. To test this idea, the subject pool was divided into "therapy" and "no therapy" groups, and their protocols were compared using a measure of object relations (SCORS). As discussed earlier, some research has suggested that the earlier a bilingual person learns a second language, the more readily he or she will become emotionally and cognitively engaged in therapy using that language (Amati-Mehler, Argentieri \& Canestri, 1993; Bond \& Lai, 1986, Pavlenko, 2002b). Contrary to the idea that the native language is the language of emotion, Rozensky and Gomez (1987) also suggested that bilinguals are more cognitively and emotionally engaged in the language that they use the most. These variables - age of second language acquisition, and relative amount of use of each language - were evaluated as moderators of cognitive and emotional engagement, and as an extension of this idea, a comparison of scores on a measure of acculturation and measures of emotional expression was made.

Table 1

Hypotheses and Variables

\begin{tabular}{|c|c|c|}
\hline Hypotheses & RCS Variables & Construct \\
\hline \multirow{3}{*}{$\begin{array}{l}\text { Emotional Engagement will be greater in the } \\
\text { native language (Spanish); more pronounced it } \\
\text { therapy group. }\end{array}$} & Afr & $\begin{array}{l}\text { Responsiveness to emotional } \\
\text { stimuli }\end{array}$ \\
\hline & $\mathrm{FC}: \mathrm{CF}+\mathrm{C}$ & $\begin{array}{l}\text { Affect modulation conceptualize } \\
\text { as a continuum from FC (most } \\
\text { reserved affect) to C (most } \\
\text { uninhibited) }\end{array}$ \\
\hline & SUMC' & Affective constraint \\
\hline \multirow{3}{*}{$\begin{array}{l}\text { Cognitive Involvement and Complexity will b } \\
\text { greater in the native language (Spanish); more } \\
\text { pronounced in therapy group. }\end{array}$} & Lambda & Cognitive involvement \\
\hline & $\mathrm{Zd}$ & $\begin{array}{l}\text { Effort and economy of perceptua } \\
\text { processing }\end{array}$ \\
\hline & Blends: $\mathrm{R}$ & Emotional complexity \\
\hline \multirow{4}{*}{$\begin{array}{l}\text { Differences in self-perception between first } \\
\text { (Spanish) and second (English) languages will } \\
\text { be greater in therapy group. }\end{array}$} & $(3 r+(2) / R)$ & $\begin{array}{l}\text { Self-evaluation (Egocentricity } \\
\text { Index) }\end{array}$ \\
\hline & $\mathrm{Fr}+\mathrm{rF}$ & Narcissistic orientation \\
\hline & FD & Introspective tendencies \\
\hline & $\mathrm{V}$ & $\begin{array}{l}\text { Negative introspection (self } \\
\text { loathing) }\end{array}$ \\
\hline $\begin{array}{l}\text { - Affect tone of object relations ratings will vary } \\
\text { according to language. }\end{array}$ & $\begin{array}{l}\text { SCORS Affect Tone } \\
\text { Scale }\end{array}$ & $\begin{array}{l}\text { Emotional loading of self- and } \\
\text { other representations }\end{array}$ \\
\hline
\end{tabular}


Table 2

Exploratory Questions and Variables3

\begin{tabular}{|c|c|c|}
\hline Questions & RCS Variables & Construct \\
\hline \multirow{3}{*}{$\begin{array}{l}\text { Is there a relationship between level of } \\
\text { acculturation and expression of affect in first a } \\
\text { second languages? }\end{array}$} & Afr & Responsiveness to emotional stim \\
\hline & $\mathrm{FC}: \mathrm{CF}+\mathrm{C}$ & $\begin{array}{l}\text { Affect modulation, conceptualizec } \\
\text { as a continuum from FC (most } \\
\text { reserved affect) to C (most } \\
\text { uninhibited) }\end{array}$ \\
\hline & SUMC' & Affective constraint \\
\hline $\begin{array}{l}\text { - Is emotional engagement greater in language } \\
\text { used most? } \\
\text { Does emotional engagement in English correla } \\
\text { with age of English acquisition? }\end{array}$ & Afr & Responsiveness to emotional stim \\
\hline $\begin{array}{l}\text { - Is cognitive engagement greater in language } \\
\text { used the most? } \\
\text { Does cognitive engagement in the second } \\
\text { language (English) correlate with age of } \\
\text { acquisition? }\end{array}$ & Lambda & Cognitive involvement \\
\hline
\end{tabular}

\section{Method}

\section{Participants}

The subjects were 26 Spanish/English bilinguals who were recruited from college campuses and outpatient mental health clinics in the New York area. They ranged in age from 18 to $48,(M=27.7, S D=8.9)$ and had diverse cultural heritages. Half were born in the United States of immigrant parents; the other half were born outside of the United States. 20 were female, and 6 were male. With the exception of one subject who had completed a GED, all subjects were either in college or had completed bachelor or graduate degrees. 16 subjects were college students, 6 were employed, 1 was unemployed, and 3 did not specify their occupation. The majority of subjects had never had psychological testing, and none had been tested within ten years.

The procedures for this study bear some limitations due to the fact that the data were collected from 1996-1999, prior to the development of the sophisticated measures of biculturalism and bilingualism that are currently available. Marin and Gamba's (1996) Bilingual Acculturation Scale (BAS) was used to assess the subjects' relative acculturation in English and Spanish domains. According to this scale indicated that all subjects were in the bicultural range. At the time of the planning of this study, it was believed that bilinguals could judge their proficiency in each language as well or better than any of the existing measures (Ardila, 1998, Roberts 1998; Costantino, personal

\footnotetext{
${ }^{3}$ For an alphabetized list of variables and a somewhat larger description of them, please see Appendix A.
} 
communication, March 25, 1996). Therefore, all potential subjects who stated that they were comfortable speaking both English and Spanish were considered to be fluent bilinguals, and were asked to participate. All subjects stated that their first language was Spanish. Dewaele's (2009) study of bi- and multilinguals, which examined the relationship of age of language acquisition and self-perceived linguistic competence, language choice for expression of emotion, and language choice for mental calculation was also far in the future at the time the data for this study were gathered. Lacking Dewaele's conclusions, age of second language acquisition was compared to emotional and cognitive engagement on the RCS, but no formal hypotheses were made regarding this comparison. In this sample, the age of English Acquisition ranged from 3-42 years $(M=11, M d n=6.5)$.

Half the subjects were assigned to the therapy group, and the other half, to the no therapy group. Therapy group members $(N=13)$ were those subjects who had sought therapy more than once $(N=9)$, and/or had been in a treatment in the past for at least a year $(N=$ $4)$, and/or were currently in therapy $(N=10)$. The no therapy group members $(N=13)$ either had never sought therapy $(N=10)$, or had one therapy experience in the past that lasted less than 3 months $(N=3)$. The two genders were equally represented within these groups, and the groups were matched for socioeconomic status. The groups did vary in terms of immigrant status, occupation, and age. Significantly more members of the therapy group were born outside of the United States $(N=9)$ than members of the no therapy group $(N=4)$. The majority of subjects in the no therapy group were students $(N$ $=10)$, while the therapy group included a more balanced mix of students $(N=6)$ and professionals $(N=5)$. The mean age of the therapy group was $33(S D=7.43)$ years, and the mean age of the no therapy group was $23(S D=7.57)$ years. Subjects were paid $\$ 15$ for their participation.

\section{Materials}

Participants were asked to complete the Bidimensional Acculturation Scale (BAS; Marin \& Gamba, 1996) to assure bicultural status. Data regarding age, national origin, socioeconomic status, age and context of language acquisition, and therapy experience were gathered using a self-report questionnaire developed by this author.

The Rorschach Comprehensive System (RCS) was administered and scored according to the guidelines of the Comprehensive System (Exner, 1993). The RCS employs the ten standard Rorschach inkblots to elicit perceptions from subjects which are scored along several dimensions. These are too numerous to list here, but they include such dimensions as complexity of the subject's percept based on integration of various areas of the blot, emotional expressiveness based on the use of colour in the blot, nx need for physical intimacy as shown by perceptions of texture. Four Thematic Apperception Test (TAT; H. A. Murray, 1943) cards were also administered to all participants (\#2, \#5, \#7BM, \#7GF). TAT cards are realistic but ambiguous pictures that are used to elicit stories from the subject with minimal cueing from the examiner. TAT protocols were scored using the Social Cognition and Object Relations Scales (SCORS) Affect Tone scale (Westen, Lohr, Silk, Kerber \& Goodrich, 1985). Both the Rorschach and TAT are meant to reveal 
conscious and unconscious data about the subject, for example, perception of self and other, mood, defensive structures, impulsivity, ease of self-expression and clarity of thought. The RCS also suggests various diagnostic categories based on the analyses and coding of the percepts.

\section{Design and Procedure}

Each subject participated in one Spanish and one English administration of the RCS and four TAT cards, scheduled no less than four weeks apart. Each subject's administrations were conducted by the same bilingual administrator. The order of administrations was counterbalanced according to membership in the therapy and no-therapy groups so that an equal number of first and second administrations occurred in each language. Each administrator conducted the same number of administrations within each of the groups (+/- 1 subject).

Administrators and coders were seven fluent Spanish/English bilingual psychology students who had received extensive training in the administration and scoring of the Comprehensive System, the TAT, and the SCORS. As was done with the subjects, determination of the administrators' and coders' level of fluency in English and Spanish was based on self-report.

\section{Results ${ }^{4}$}

None of the hypotheses regarding variance of protocols by language or interaction between group and language was validated at the alpha .05 level. Due to non-normality, $\mathrm{RCS}$ measures of affective engagement ( $\mathrm{Afr}, \mathrm{FC}, \mathrm{CF}+\mathrm{C}$, and $\mathrm{C}$ ) were transformed using a rank transformation. A $2 \times 2 \times 2$ repeated measures MANOVA showed no difference between language protocols, Pillai's $=.14, F(4,20)=.78, p=.55$. However, $14 \%$ of the variability for these measures was accounted for by language, with relatively low obtained power. No interaction between group and language was found, Pillai's $=.16$, $\underline{F}(4,20)=.95, p=.25$. Contrary to the expectation that speaking the native language would be more conducive to cognitive involvement in the stimuli, a MANOVA of the cognitive variables $(\mathrm{Zd}$, Lambda, Blends:R) reflected more intellectual engagement in English, Pillai's $=.47, F(3,20)=5.80, p=.005 ; \eta^{2}=.47$, power $=.90$. In addition, a significant interaction between Language and First Language of Administration, Pillai's $=.49, F(3,20)=6.31, p=.003$ was found. Follow-up univariate analyses revealed a significant effect for Lambda, $F(1,22)=5.02, p=.04$, and $\mathrm{Zd}, F(1,22)=7.60, p=.01$, and a trend for Blends:R, $F(1,22)=3.41, p=.08$. The main effect for language for the $\mathrm{Zd}$ variable appeared to be an artifact of this interaction between language and First Language of Administration. No significant Language by Group effect, Pillai's $=.13$, $F(3,20)=.99, p=.42$, for RCS measures of complexity of processing was found, however, this interaction was found to account for $13 \%$ of the variability for these measures $($ power $=.23)$.

\footnotetext{
${ }^{4}$ RCS variables are explained in Appendix A.
} 
Difference scores were calculated for the measures of self-perception (Egocentricity Index, Fr+rF, FD, and V) by subtracting the Spanish scores from the English scores for each variable, thereby automatically embedding the language effect into analysis of these variables. The Egocentricity Index difference scores were transformed using a rank transformation, and an Analysis of Variance was performed for that variable. For FD, V, and $\mathrm{Fr}+\mathrm{rF}$, transformations did not normalize these difference scores due to the limited number of values obtained. These variables were analyzed using the phi coefficient. An ANOVA of the difference between scores on the two language protocols for the Egocentricity Index revealed no group main effect, $F(1,22)=.009, p=.93$, nor did the analysis of differences in introspective tendencies (FD), phi $=.36, p=.63, \mathrm{~V}, p h i=.28, p$ $=.56$, and $\mathrm{Fr}+\mathrm{rF}, p h i=.36, p=.49$, disconfirming the hypothesized interaction between group and language for RCS measures of self-perception.

An ANOVA of SCORS Affect Tone of Object Relations scores for TAT stories showed no main effect for language, Pillai's $=.01, F(1,22)=.22, p=.65$ and no interaction between group membership and language of protocol, Pillai's $=.001, F(1,22)=.02, p=$ .88. No relationship was found between the age of English acquisition and emotional engagement in English as indicated by Afr, $r=.00$, nor was any significant relationship found between age of English acquisition and cognitive involvement in English as indicated by Lambda, $r=.23$. Language used most was not related to Lambda, $\chi^{2}(2)=$ $2.39, p=.30$, or to Afr, $\chi^{2}(2)=2.15, p=.34$.

Higher levels of acculturation in the English domain as measured by the BAS scale were strongly associated with more open displays of emotional expression in English as measured by the RCS variables $\mathrm{C}, N=26, r=.40, p=.04$, and $\mathrm{CF}, N=26, r=.42, p=$ .03 , in English. No significant relationship was found between acculturation in English and the variables FC, $N=26, r=.15, p=.48$ ) or SUMC', $N=26, r=.13, p=.53$. No significant relationships were found between levels of acculturation in the Spanish domain and RCS variables FC, $N=26, r=.12, p=.57, \mathrm{CF}, N=26, r=.02, p=.92, \mathrm{C}, N$ $=26, r=.18, p=.37$, or SUMC', $N=26, r=.08, p=.70$, in Spanish protocols.

Further exploration of the data, beyond the scope of the hypotheses, revealed differences in the content and quality of RCS verbalizations. Furthermore, identification of key variables (see Appendix B) that would be used for a comprehensive (cluster) interpretation for each individual's Rorschach protocol showed that $42 \%$ of all subjects changed Erlebnistypus (EB) across language protocols. The EB variable indicates the relative amount of use of affect as compared to thought in decision-making, where "extratensive" indicates a larger role for emotion, "introversive" indicates a larger role for cognition, and "ambitent" suggests no consistent style. 6 subjects were found to be extratensive in one language and ambitent in the other, 4 were introversive in one and ambitent in the other, and 2 were introversive in one and extratensive in the other. EBPer calculations ranged from 1.8-4.0, indicating a strong commitment to EB style in both languages. Moreover, $73 \%$ of protocols changed key variables for cluster interpretation and diagnosis. 54\% changed key variables in the no therapy group, (see Table 3), and $92 \%$ changed in the therapy group (see Table 4 ). The difference between the number of 
changes in key variables of the therapy and no therapy group was significant, $\chi^{2}(1)=$ $4.89, p=.03$.

Table $3^{5}$

Cluster Interpretation Key Variables by Subject and by Language in No Therapy Group

\begin{tabular}{|c|c|c|}
\hline Subject & Key Variable Derived & frc Key Variable Derived from English Protoco \\
\hline & Spanish Protocol & \\
\hline 1. & $\mathrm{D}<\operatorname{Adj} \mathrm{D}$ & $\mathrm{D}<\operatorname{Adj} \mathrm{D}$ \\
\hline 2. & SCZI & Ref $>0$ \\
\hline 3. & DEPI & SCZI \\
\hline 4. & $\mathrm{p}>\mathrm{a}+1$ & Lambda \\
\hline 5. & Lambda & Lambda \\
\hline 6. & SCZI & CDI \\
\hline 7. & $\mathrm{CDI}$ & CDI \\
\hline 8. & SCZI & SCZI \\
\hline 9. & SCZI & $\mathrm{SCZI}$ \\
\hline 10. & $\mathrm{M}->0$ & $\mathrm{D}<\operatorname{Adj} \mathrm{D}$ \\
\hline 11. & $\mathrm{CDI}$ & DEPI \\
\hline 12. & SCZI & SCZI \\
\hline 13. & Adj $\mathrm{D}$ is minus & SCZI \\
\hline
\end{tabular}

Table $4^{6}$

${ }^{5}$ See Appendix B for explanation of key variables. 
Cluster Interpretation Key Variables by Subject and by Language in Therapy Sample (n $=13)$

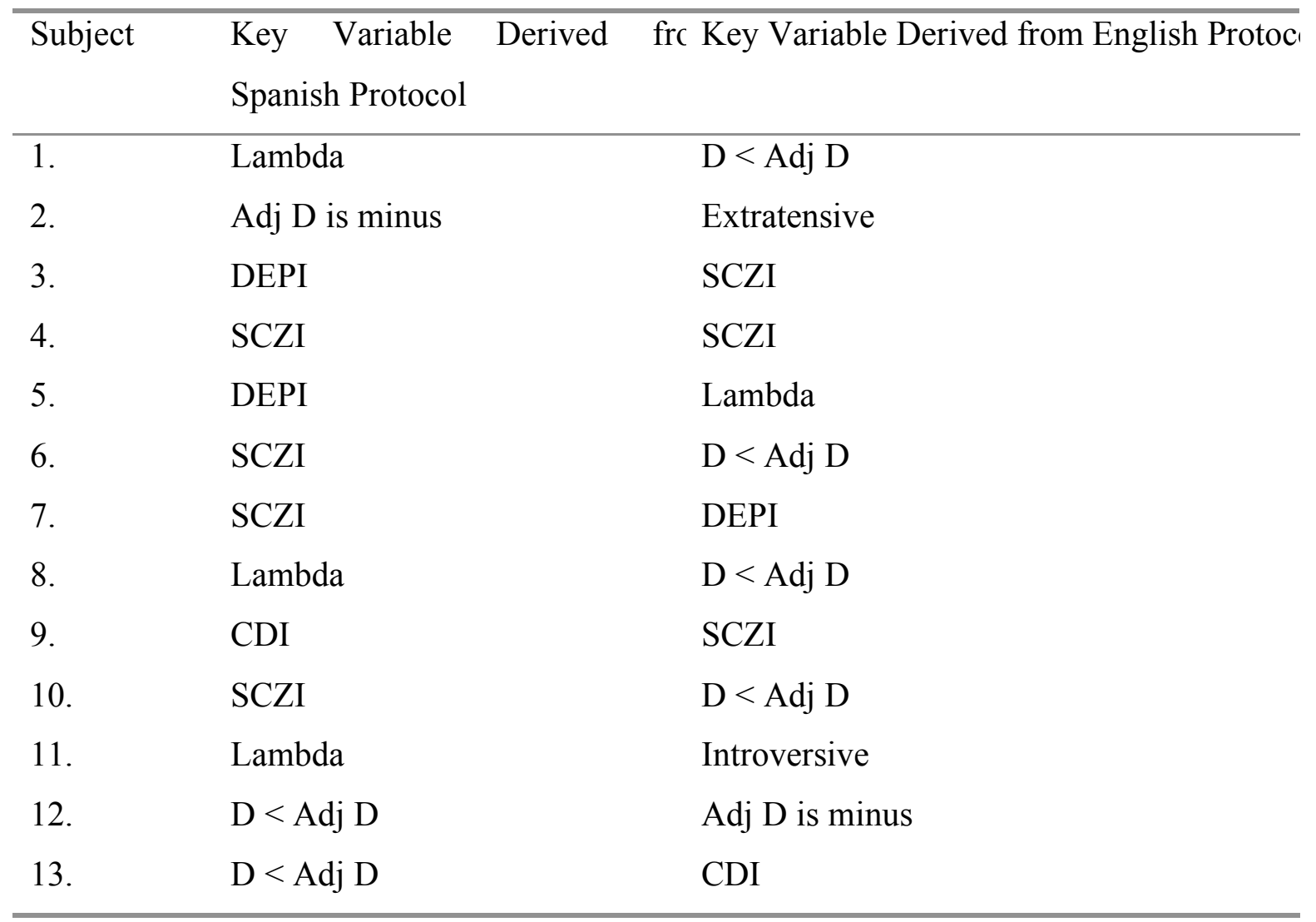

Content analysis of TAT stories given in Spanish and English also revealed differences. For example, the following stories are given by the same subject in response to TAT card \#2, a farm scene depicting three people whose age, style of dress, and activity vary, creating a highly ambiguous picture. The subject shows different levels of emotional engagement, creativity, and focus on detail, and distinctive self-presentations and approaches to conflict resolution in Spanish and English. Spanish: (first administration):

OK. This is a girl that has to go by a ranch on her way to school every day, but she is in love with the man that works on the ranch but he is married and at this moment she goes by there and sees the wife of the man she likes and she realizes that the wife is pregnant. Now she is realizing that she is only a girl and this man belongs to a more mature woman. (A conclusion?) She is going to change the way she gets to school, she

${ }^{6}$ See Appendix B for explanation of key variables. 
will take the longer path so as not to see this man anymore and accept that she still has a lot of time to grow and to meet a man that will truly be only hers. (How does the man feel?) He does not realize everything that has happened but his wife did know and that is why she went and stood there so that the girl would see her. (Something else?) No.

\section{English:}

OK. This story takes place somewhere in Ohio and what has happened before is this couple lived on a farm and the wife was twice the age of the husband and the wife had a really hard time getting pregnant, she was having a lot of miscarriages and the husband was getting frustrated. He was the good looking youthful and very hard working man who only wanted a child in life and it was the one thing his wife couldn't give him. His neighbor was a 16 year-old shy, pretty girl. Everyday she would pass by and see him working on the field and wonder why he was so unhappy. One day she finally decided to have a conversation with him in which he asked her, I mean told her, that he had been watching her too and was in love with her and asked her if she would be the mother of that child he wanted. So the young girl agreed and fell in love with the man and eventually really became pregnant, so one day as she passed by the farm again she looked out and saw the man's wife and she was 7 months pregnant... the

wife was 7 months pregnant. Enraged that this man had lied to her and had tricked her into also having his child the young girl ran up to the woman and beat her to death with her school books. When the man saw what happened he grabbed the girl and with tears rolling down his eyes exclaimed "That lady was my Mom, not my wife!" and the man never spoke to the young girl ever again. Oh, and his wife, she 
eventually had 3 kids and they lived happily ever after. (How did girl feel after he didn't speak to her?) She lost her mind and took it out on the kid she eventually had. (How did the wife feel?) He never told her.

As shown in Table 5, the means of several of the RCS variables gleaned from this sample differed significantly from the published norms (Exner, 1993).

Table $5^{7}$

Comparison of Means with Normative Data for Nonpatient Adults $(N=26)$

\begin{tabular}{|c|c|c|c|c|c|}
\hline Variable & Language & $\mathrm{M}$ & $\mathrm{df}$ & $\mathrm{p}$ & $+/-/ \mathrm{s}^{\mathrm{a}}$ \\
\hline \multirow[t]{2}{*}{$\mathrm{R}$} & English & 23. & . & . & \\
\hline & Spanish & 25. & 1. & . & \\
\hline \multirow[t]{2}{*}{ Lambda } & English & 1. & 3. & .0 & \\
\hline & Spanish & 1. & 3. & .0 & \\
\hline \multirow[t]{2}{*}{$\mathrm{Zd}$} & English & . &.- & . & \\
\hline & Spanish & -1 . & -2 . & . & \\
\hline \multirow{2}{*}{ Blends } & English & 4. & -. & . & \\
\hline & Spanish & 3. & -3 & .0 & \\
\hline \multirow[t]{2}{*}{ Blends: $R$} & English & . & -.8 & $\therefore$ & \\
\hline & Spanish & . & -5 & $<.0$ & \\
\hline \multirow[t]{2}{*}{$3 r+(2) / R$} & English & $\therefore$ & . & . & \\
\hline & Spanish & $\therefore$ & -. & . & \\
\hline \multirow[t]{2}{*}{$\mathrm{Fr}+\mathrm{rF}$} & English & . & 1. & . & \\
\hline & Spanish & . & 3. &. & \\
\hline \multirow[t]{2}{*}{ FD } & English & 1. & -1. & . & \\
\hline & Spanish & . &.- & . & \\
\hline \multirow[t]{2}{*}{ V } & English & $\therefore$ & 1. & . & \\
\hline & Spanish & . & .0 & . & \\
\hline \multirow[t]{2}{*}{ Afr } & English & . & -2 . & .' & \\
\hline & Spanish & . & -2 . & . & \\
\hline \multirow[t]{2}{*}{$\mathrm{FC}$} & English & 1. & -9. & $<.0$ & \\
\hline & Spanish & 1. & -6. & $<.0$ & \\
\hline \multirow[t]{2}{*}{$\mathrm{CF}$} & English & . & -7 & $<.0$ & \\
\hline & Spanish & $\therefore$ & -10 . & $<.0$ & \\
\hline \multirow[t]{2}{*}{$\mathrm{C}$} & English & 1. & 5. & $<.0$ & \\
\hline & Spanish & 1. & 4. & $<.0$ & \\
\hline \multirow[t]{2}{*}{ SUMC' } & English & 2. & 2. &. & \\
\hline & Spanish & 2. & 1. & . & \\
\hline
\end{tabular}

${ }^{7}$ See Appendix B for explanation of key variables. 


\begin{tabular}{|c|c|c|c|c|c|}
\hline Variable & Language & $\underline{\mathrm{M}}$ & $\mathrm{df}$ & $\underline{p}$ & $+/-/ \mathrm{s}^{\mathrm{a}}$ \\
\hline \multirow[t]{2}{*}{ WSUM6 } & English & 17. & 5. & $<.0$ & \\
\hline & Spanish & 13. & 4. & $<.0$ & \\
\hline \multirow[t]{2}{*}{$\mathrm{X}-\%$} & English & . & 7. & $<.0$ & \\
\hline & Spanish & . & 8. & $<.0$ & \\
\hline \multirow[t]{2}{*}{ D Score } & English & - . & -2 . & . & \\
\hline & Spanish & -. & -2 & . & \\
\hline \multirow[t]{2}{*}{$\mathrm{T}$} & English & . & -4. & $<.0$ & \\
\hline & Spanish & $\therefore$ & -2 . & . & \\
\hline
\end{tabular}

${ }^{a}$ Indicates that the mean is significantly higher than the normative mean $(+)$, significantly lower than the normative mean (-), or similar to the normative data mean (s).

\section{Discussion}

The primary purpose of this study was to determine whether projective assessment instruments can confirm and describe the language-based experiences of multiplicity reported by bilinguals and the clinicians who work with them. If so, a second goal was to formulate empirically-based generalizations about these differences. The third objective was to identify factors that might serve as moderator variables in these shifts in aspects of personality.

Although the hypotheses set forth in this study were not confirmed, RCS protocols rendered by Spanish/English bilinguals were found to differ according to the language of administration. In fact, in the majority of cases, RCS protocols given by bilinguals in their two languages varied so extensively from one another that they indicated different key variables for Comprehensive System cluster interpretation (see Tables 3 and 4). In the Comprehensive system, key variables are essential guides to the formulation of an interpretation and diagnosis, permitting "the identification of the data that would contribute the most substantial information about the core psychological features of the subject." (Exner, 1991, p. 144). Given that key variables have been demonstrated to be such valuable beacons for interpretation and that the Comprehensive System has been shown to have good test retest reliability (Exner, 1980; Haller \& Exner, 1985), we are left to conclude that the shift in key variables constitutes a substantive finding that reflects the bilingual's discrete language-based cultural and personal contexts. As found by Ervin (1964) several decades ago, content analysis of TAT protocols administered in the bilingual's two languages also illuminates these differences.

Based on these data, a few assumptions can be made about how protocols might vary according to language. Contrary to the hypothesis that the native language would elicit greater cognitive effort, it was found that more cognitive engagement and complexity were involved in creating English protocols. This finding was true even for subjects who reported that their Spanish was slightly stronger than their English, and for those who stated neither English nor Spanish was stronger. This association between English and cognitive effort may relate to the fact that most of the subjects learned and spoke English 
in school. Previous research that focused on the contexts for language learning supports this interpretation (Bond \& Lai, 1986; Dewaele \& Pavlenko, 2002; Ervin, 1964).

These data also suggest that further light may be shed on language-based differences if moderating factors are considered. Two of the proposed moderating factors, therapy experience and level of acculturation, did relate to the differences between Spanish and English protocols. Significantly more subjects who had therapy experience produced protocols with key variables that varied from Spanish to English. This variation seems to lend some credence to the hypotheses regarding the differences between the therapy and no therapy groups. However, these data suggest that the differences are based on constellations of factors rather than on variance in a single dimension, such as emotional expression. Based on this finding, we might theorize that the difference in key variables reflects a division between two language-related inner realms, and that this division may contribute to the subjective distress that led these subjects into therapy. Although this theory is appealing, this study offers it very little empirical confirmation. The differences between key variables is not quantifiable - for example, a shift from DEPI (Depression) to SCZI (Schizophrenia) cannot be said to be greater than a shift from CDI (Coping Deficit Disorder) SCZI (Schizophrenia) - and therefore, although significantly more members of the therapy group switched key variables, it is impossible to tell whether the shifts in the no therapy group were more dramatic than those in the therapy group. Moreover, there were important demographic differences between the therapy and no therapy groups (e.g. age, country of origin, percentage of students vs. professionals). These differences may have acted as confounds, relating in some way to the switches in key variables.

In sum, it is difficult to say whether the moderating variable was indeed therapy experience, or whether some other salient characteristics distinguished the groups. The other proposed moderating factor, acculturation, was shown to play a significant role in the content of the RCS protocols. Greater levels of acculturation in the English domain on the BAS scale related to more freedom in displays of emotion in English (greater incidence of $\mathrm{C}$ determinants). At first, this relationship seems to make good intuitive sense, suggesting a connection between feeling "at home" with a language (and its implicit culture) and freer expression. However, this interpretation begs the question of why this relationship was not paralleled in the Spanish protocols. An unpredicted moderating factor, order of language administration, had a significant effect on the content of RCS protocols. Protocols administered in Spanish first tended to show significantly less cognitive complexity and engagement than any other protocols, with higher levels of Lambda, and lower levels of $\mathrm{Zd}$ and Blends: R. As already discussed, English protocols showed more cognitive effort in general, but they were especially high in $\mathrm{Zd}$ and Blends: $\mathrm{R}$ when they were produced by the second administration.

The literature on psychotherapy with culturally diverse groups suggests some answers to the questions that these data raise about the role of acculturation and order of language administration. The literature emphasizes that Hispanic Americans, relative to other groups, may take a reserved approach with strangers (Casas \& Vasques, 1989) and may be hesitant to disclose personal information (Rosado, 1980; Torres, 1983). As discussed below in the context of overall variations in norms, Vinet's (2000) findings also support a 
cultural basis for this reserved attitude. Although generalizations about the heterogeneous group of Spanish speaking people that participated in this study must be made with caution, we might conjecture that some of the findings are due to this inclination towards formality. If we assume that language both stimulates and reflects cultural frames of reference, then we would expect more constraint when subjects speak Spanish. We might also assume that this tendency would be heightened during the first administration, especially if it is performed in Spanish. More constraint in general would be expected from subjects who are less acculturated to the English domain.

Although the sample size was small, the RCS norms derived from this study are worth some discussion. Clearly, the protocols gleaned from this group of people varied from the original norms in important ways. With regard to the Lambda, FC, X-\%, and $\mathrm{T}$ variables, these results corroborate those found in a recent study of nonpatients by Shaffer, Erdberg, and Horoian (1999), and reaffirm their statement that revised norms for general use are needed. However, the means of the measures of quality of ideation and affect modulation were significantly different from those found by Shaffer et al and from the published norms. Vinet's (2000) interpretation of RCS data compiled from four Iberoamerican countries (Chile, Portugal, Spain, and Venezuela) offers some insight into the variation between the original RCS norms and those gleaned from this study. As was found here, Vinet's data shows that Iberoamerican subjects scored higher on the variables Lambda and $\mathrm{X}-\%$, and lower on Zd, Afr, and T. Drawing on Hofstede's study of work-related values in 40 countries (Hofstede, 1980), Vinet explains that the scores on Lambda, Zd, and Afr reflect attitudes that are typically displayed by Iberoamericans during high stress situations in which interaction with authority figures is required. Specifically, according to Hofstede's codification, the scores can be interpreted as reflections of high Power Distance, which reflects respect for authority figures, and high Uncertainty Avoidance, as demonstrated by mistrust. Viewing the data within a cultural context, Vinet sees the Lambda, $\mathrm{Zd}$, and Afr scores as signifying an adaptive response to the testing situation that is consistent with Iberoamerican values rather than as a defensive withdrawal of emotional and cognitive engagement. Vinet also points out that Iberoamericans perceive a sharp dichotomy between ingroup and outgroup, and while conformity is implicit in the collectivist orientation of Iberoamericans, they can be quite nonconformist in response to rules generated by the outgroup. She attributes the high $\mathrm{X}-\%$ and low number of popular responses found on Iberoamerican protocols as a function of this reactive unconventionality. To explain the relative low number of $T$ responses on the Iberoamerican protocols, Vinet employs findings from research focused on the presence of T in "contact cultures" protocols (Fuster, Sifre, Barriusi, Lobato, Martinez, 1997). Fuster et al suggest that in these cultures, in which physical closeness throughout the lifespan is normative, the need for this kind of intimacy is satisfied, therefore, protocols generated within this cultural context will have fewer $\mathrm{T}$ responses. Based on Vinet's statement that all countries touched by Iberoamerican influences are part of the same cultural unit, we can consider her interpretations as relevant to the current sample. If we do so, the high WSUM6 mean found here can be explained by the same pull towards unconventionality that generated the high X-\% scores. Costantino, Flanagan, and Malgady (1995) reported that a higher number of color responses can be expected from Hispanics. The norms generated by this study show that color responses varied from the original norms more by quality than by quantity, that is, there were significantly more $\mathrm{C}$ 
responses, while the mean value for $\mathrm{FC}$ and $\mathrm{CF}$ responses was similar to the normative group. Again, Vinet's (2000) explains this phenomenon by drawing on the data regarding contact cultures. In these cultures, there is little inhibition in the expression of emotions.

The outcome of this study encourages more exploration into the many levels of interaction between language, culture, and the RCS. In particular, employment of current instruments that measure biculturalism and language fluency would allow further refinement of the subject pool. The role of age of second language acquisition in the assessment of bilinguals is also worthy of further exploration. However, regardless of the methodological limitations of this study, its findings lend empirical support for the clinical and anecdotal evidence already cited depicting language based multiplicity, and provide further evidence that language and culture must be regarded as key elements in the psychoanalysis of multilingual people.

\section{Acknowledgment}

I am grateful to the Society for Personality Assessment for their help in funding this study. I also wish to thank Barry Ritzler, Rhiannon Allen, and Paul Ramirez for their invaluable input into the design of the study. I am especially indebted to the many administrators and coders who worked so hard gathering and scoring data, especially Ysa Nunez, Richard Rapp, Tania Serrata, and Glorianna Valls. I also thank Sarai Batchelder for her help with statistical analysis, Chris Nutini for lending his translation skills, and Brian Levine and Jorge Pina for their help in recruiting subjects at the Postgraduate Center and the Hispanic Psychoanalytic Studies Center. I am also grateful to George Frank, Lew Aron, and Richard Dana for their thoughtful feedback on an earlier version of this paper which was presented at the 2001 Midwinter Meeting of the Society for Personality Assessment in Philadelphia, PA. 


\section{References}

Abu-Lughod, L., \& Lutz, A. (Eds.) (1990). Language and the politics of emotion. Cambridge, UK: Cambridge University Press.

Amati-Mehler, J., Argentieri, S., \& Canestri, J. (1993). The babel of the unconscious: Mother tongue and foreign languages in the psychoanalytic dimension. Madison, CT: International Universities Press.

Anooshian, L. J., \& Hertel, P. T. (1994). Emotionality and free recall: language specificity in bilingual memory. Cognition and Emotion, 8(6), 503-514.

Antinucci-Mark, G. (1990). Speaking in tongues in the consulting room or the dialectic of foreigners. British Journal of Psychotherapy, 6, 375-383.

Ardila, A. (1998). Bilingualism: A neglected and chaotic area. Aphasiology, 12(2),131134.

Ben-Rafael, M. (2004). Language contact and attrition: The spoken French of Israeli Francophones. In M. S. Schmid, B. Kopke, M. Keijzer, \& L. Weileman (Eds.), First language attrition: Interdisciplinary perpectives on methodological issues (pp. 165-187). Amsterdam, Netherlands: John Benjamins.

Bond, M. H., \& Lai, T. (1986). Embarrassment and code-switching into a second language. Journal of Social Psychology, 126, 179-186.

Bromberg, P. M. (1996). Standing in the spaces: the multiplicity of self and the psychoanalytic relationship. Contemporary Psychoanalysis, 32(4), 509-535.

Buxbaum, E. (1949). The role of a second language in the formation of ego and superego. Psychoanalytic Quarterly, 18(3), 279-289.

Casas, J. M., \& Vasquez, M. J. T. (1989). Counseling the Hispanic client: A theoretical and applied perspective. In P. B. Pedersen et al. (Eds.) Counseling Across Cultures (pp. 116-133). Honolulu, HI: University of Hawaii Press.

Chefetz, R. A., \& Bromberg, P. M. (2004). Talking with "Me" and "Not-Me": A dialogue. Contemporary Psychoanalysis, 40, 409-464.

Clauss, S. C. (1998). Language: The unspoken variable in psychotherapy practice. Psychotherapy, 35(2), 188-196.

Davies, J. (1999). Getting cold feet, defining "safe-enough" borders: Dissociation, multiplicity, and integration and the analyst's experience. Psychoanalytic Quarterly, 68, 184-208.

Del Castillo, J. (1970). The influence of language upon symptomotology in foreign-born patients. American Journal of Psychiatry, 127, 242-244.

Dewaele, J.-M. (2009). Age effects on self-perceived communicative competence and language choice among adult multilinguals. EUROSLA Yearbook, 9(1), 245-268.

Dewaele, J.-M. (2004a). The emotional force of swearwords and taboo words in the speech of multilinguals. Journal of Multilingual and Multicultural Development, 25(2), 204-222.

Dewaele, J.-M. (2004b). Blistering barnacles! What language do multilinguals swear in? Estudios de Sociolinguistica, 5(1), 83-105.

Dewaele, J.-M. (2004c). Perceived language dominance and language preference for emotional speech: The implications for attrition research. In M. S. Schmid et al. (Eds.), First language attribution: Interdisciplinary perspectives on methodological issues (pp. 81-104). Amsterdam, Netherlands: Benjamins. 
Dewaele, J.-M., \& Pavlenko, A. (2002). Emotional vocabulary in interlanguage. Language Learning, 52(2), 263-322.

Doi, T. (1973). The anatomy of independence. Tokyo, Japan: Kodansh International.

Ervin, S.M. (1964). Language and T.A.T. content in bilinguals. Journal of Abnormal Social Psychology, 68, 500-507.

Ervin-Tripp, S. M. (1968). An analysis of the interaction of language, topic, and listener. In J. Fishman (Ed.), Readings in the sociology of language (pp. 192-211). The Hague, Netherlands: Mouton.

Exner, J. E. (1980). But it's only an inkblot. Journal of Personality Assessment, 44, 562577.

Exner, J. E. (1991). The Rorschach: A comprehensive system. Interpretation: Vol. 2. ( $^{\text {nd }}$ ed.). New York, NY: John Wiley \& Sons.

Exner, J. E. (1993). The Rorschach: A comprehensive system. Basic foundations: Vol.1. (3rd ed.), New York, NY: John Wiley \& Sons

Fuster, J., Sifre, S., Barriusi, I., Lobato, E., \& Martinez, M. (1997). Comparación de una muestra de población normal valenciana con la muestra barcelonasa [Comparison of a sample of normal population from Barcelona with the sample from Barcelona]. Revista de la Sociedad Española del Rorschach y Metodos Proyectivos, 10, 5865.

Geertz, C. (1984). "From the native's point of view": On the nature of anthropological understanding. In R. Shweder, \& R. A. LeVine (Eds.), Culture theory: Essays on mind, self, and emotion (pp. 137-157). Cambridge, UK: Cambridge University Press.

Goddard, C. (1991). Anger in the western desert: A case study in the cross-cultural semantic means of emotion. Man, 26, 265-279.

Greenson, R.R. (1950). The mother tongue and the mother. International Journal of Psychoanalysis, 31(18), 18-23.

Grosjean, F. (1982). Life with two languages. Cambridge, MA: Harvard University Press.

Haller, N., \& Exner, J. E. (1985). The reliability of Rorschach variables for inpatients presenting symptoms of depression and/or helplessness. Journal of Personality Assessment, 49, 516-521.

Harris, C. L., Aycicegi, A., \& Gleason, J. B. (2003). Taboo words and reprimands elicit greater autonomic reactivity in a first language than in a second language. Applied Linguistics, 24(4), 561-579.

Heelas, P. (1983). Indigenous representations of emotions: the Chewong. Journal of the Anthropological Society of Oxford, 14(1), 87-103.

Hill, S. (2008). Language and intersubjectivity: Multiplicity in a bilingual treatment. Psychoanalytic Dialogues, 18, 437-455.

Hoffman, E. (1989). Lost in translation: A life in a new language. New York, NY: Dutton.

Hofstede, G. (1980). Cultures consequences: International differences in work-related values. Newbury Park, CA: Sage.

Javier, R. A. (1995). Vicissitudes of autobiographical memories in a bilingual analysis. Psychoanalytic Psychology, 12(3), 429-438.

Kaplan, A. (1993). French lessons. Chicago, Il: The University of Chicago Press.

Kitron, D. (1992). Transference and countertransference implications conducted in a foreign language. Bulletin of the Menninger Clinic, 56, 232-245. 
Krapf, E. E. (1955). The choice of language in polyglot psychoanalysis. Psychoanalytic Quarterly, 24, 343-357.

Lijtmaer, R. M. (1999). Language shift and bilinguals: transference and countertransference implications. Journal of the American Academy of Psychoanalysis, 27(4), 611-623.

Lutz, C. A. (1988). Unnatural emotions: Everyday sentiments on a Micronesian atoll and their challenge to western theory. Chicago, Il: University of Chicago Press.

Lvovich, N. (1997). The multilingual self: An inquiry into language learning. Mahwah, NJ: Lawrence Erlbaum Associates.

Koreneva, E. (2003). She-idiot: An autobiography. Moscow, Russia: ACT Astrel'.

Malawista, K. L., \& Drake, D. S. (2002). Conversion symptoms and psychoanalysis in a second language: some thoughts on the analysis of Mr. B. Psychoanalytic Social Work, 9A, 3-25.

Marcos, L. R., \& Alpert, M. (1976). Strategies and risks in psychotherapy with bilingual patients: The phenomenon of language independence. American Journal of Psychiatry, 133(11), 1275-1278.

Marcos, L. R., Eisma, J. E., \& Guimon, J. (1977). Bilingualism and sense of self. The American Journal of Psychoanalysis, 37, 285-290.

Marcos, L. R., \& Urcuyo, L. (1979). Dynamic psychotherapy with the bilingual patient. American Journal of Psychotherapy, 33(3), 331-338.

Marcos, L. R. (1988). Understanding ethnicity in psychotherapy with Hispanics. American Journal of Psychoanalysis, 48, 35-42.

Marin, G., \& Gamba, R. J. (1996). A new measurement of acculturation for Hispanics: The bidimensional acculturation scale for Hispanics (BAS). Hispanic Journal of Behavioral Sciences, 18(3), 297-316.

McMahill, C. (2001). Self-expression, gender, and community: A Japanese feminist English class. In A. Pavlenko, A. Blackledge, I. Piller, \& M. Teutsch-Dwyer (Eds), Multilingualism, second language learning, and gender (pp. 307-344). Berlin, Germany: Mouton De Gruyter.

Morsbach, H., \& Tyler, W. (1986). A Japanese emotion: Amae. In R. Harre (Ed.), The social construction of emotions (pp. 289-307). Oxford, UK: Blackwell.

Murray, H. (1943). Thematic Apperception Test manual. Cambridge, MA: Harvard University Press.

Ochs, E., \& Capps, L. (1996). Narrating the self. Annual Review of Anthropology, 25, 1943.

Panayiotou, A. (2004a). Bilingual emotions: The untranslatable self. Estudios de Sociolingüística, 5(1), 1-19.

Panayiotou, A. (2004b). Switching codes, switching code: Bilinguals' emotional responses in English and Greek. Journal of Multilingual and Multicultural Development, 25(2\&3), 124-139.

Pavlenko, A. (1998). Second language learning by adults: Testimonies of bilingual writers. Issues in Applied Linguistics, 9(1), 3-19.

Pavlenko, A. (2002a). Emotions and the body in Russian and English. Pragmatics and Cognition, 10(1-2), 201-26.

Pavlenko, A. (2002b). Bilingualism and emotions. Multilingua, 21(1), 45-78.

Pavlenko, A. (2008). Emotion and emotion-laden words in the bilingual lexicon. Bilingualism: Language and Cognition, 11(2), 147-164. 
Perez Foster, R. (1992). Psychoanalysis and the bilingual patient: Some observations on the influence of language choice on the transference. Psychoanalytic Psychology, $9(1), 61-75$.

Perez Foster, R. (1996). Assessing the psychodynamic function of language in the bilingual patient. In R. Perez Foster, M. Moskowitz, \& R. A. Javier (Eds.), Reaching across the boundaries of culture and class (pp. 243-263). New Jersey, NJ: Jason Aronson.

Perex-Foster, R. (1998). Special issues in working with the bilingual person: The power of language in the clinical process: Assessing and treating the bilingual person. New Jersey, NJ: Jason Aronson.

Piller, I., \& Takahashi, K. (2006). A passion for English: Desire and the language market. In A. Pavlenko (Ed.), Bilingual minds: Emotional experiencing, expression, and representation (pp. 59-83). Clevedon, UK: Multilingual Matters.

Rintell, E. (1984). But how did you feel about that? The learner's perception of emotion in speech. Applied Linguistics, 5(3), 255-264.

Roberts, P. M. (1998). Reply: Bilingual aphasia: Some answers and more questions. Aphasiology, 12(2), 141-146.

Rosado, J. (1980). Important psychocultural factors in the delivery of mental health services to lower-class Puerto Rican clients: A review of recent studies. Journal of Community Psychology, 8(2), 215-226.

Rosaldo, M. (1984). Toward an anthropology of self and feeling. In R. Shweder, \& R. A. LeVine (Eds.), Culture theory: Essays on mind, self, and emotion (pp. 137-157). Cambridge, UK: Cambridge University Press.

Rozensky, R. H., \& Gomez, M. Y. (1983). Language switching in psychotherapy with bilinguals: two problems, tow models, and case examples. Psychotherapy: Theory, Research and Practice, 20(2), 152-160.

Rubin, D.C., \& Friendly, M. (1986). Predicting which words get recalled: Measures of free recall, availability, goodness, emotionality, and pronunciability for 925 nouns. Memory and Cognition, 14, 79-94.

Russell, J. (1991). Culture and categorization of emotions. Psychological Bulletin, $110(3), 426-450$.

Sante, L. (1996, May 12). Living in tongues. The New York Times Magazine, 31-34.

Shaffer, T. W., Erdberg, P., \& Haroian, J. (1999). Current nonpatient data for the Rorschach, WAIS-R, and MMPI-2. Journal of Personality Assessment, 73(2), 305316.

Stern, D. (2003). Unformulated experience. New York, NY: Routledge.

Stern, D. (2004). The eye sees itself: Dissociation, enactment, and the achievement of conflict. Contemporary Psychoanalysis, 40, 197-237.

Torres, W.J. (1983). Puerto Rican and Anglo conceptions of appropriate mental health services. In K.E. Davis, \& R. Bergner (Eds.), Advances in descriptive psychology (pp. 147-170), Greenwich, CT: JAI Press Inc.

Vinet, E. V. (2000). The Rorschach Comprehensive System in Iberoamerica. In R. Dana (Ed.), Handbook of cross-cultural and multicultural personality assessment (pp. 345-365). Mahwah, NJ: Lawrence Erlbaum

Westen, D., Lohr, N., Silk, K. Kerber, K., \& Goodrich, S. (1985). Object relations and social cognition TAT scoring manual. Ann Arbor, MI: University of Michigan. 
Wierzbicka, A. (1992). Talking about emotions: Semantics, culture, and cognition. Cognition and Emotion, 6, 285-319. 


\section{Appendix A}

\begin{tabular}{|c|c|}
\hline Variable & Alphabetized Description of Variables and Constructs \\
\hline $3 r+(2) / R$ & $\begin{array}{l}\text { This is the Egocentricity Index, which measures appraisal of self } \\
\text { worth. }\end{array}$ \\
\hline Afr & $\begin{array}{l}\text { Measure of the subject's openness to processing emotional } \\
\text { stimuli. }\end{array}$ \\
\hline Blends & $\begin{array}{l}\text { Total number of responses that include more than one determinat } \\
\text { for example, a perception of movement and texture. The use of } \\
\text { blends suggests a willingness to become involved in thinking } \\
\text { about new stimuli. }\end{array}$ \\
\hline Blends:R & Blends: $\mathrm{R}$ is a measure of psychological complexity. \\
\hline $\mathrm{C}$ & $\begin{array}{l}\text { Measure of the reference to color in the blots, and is associated } \\
\text { with great emotional displays. }\end{array}$ \\
\hline $\mathrm{CF}$ & $\begin{array}{l}\text { Measure of the reference to color in the blots, and is associated } \\
\text { with fairly pronounced emotional displays. }\end{array}$ \\
\hline D Score & $\begin{array}{l}\text { Measures impulsive tendencies, thought to be a reaction to an } \\
\text { overload of stress. }\end{array}$ \\
\hline FC & $\begin{array}{l}\text { Measure of responsiveness to color in the blot, and is associated } \\
\text { with relatively mild emotional demonstration. }\end{array}$ \\
\hline FD & Measures capacity for introspection. \\
\hline $\mathrm{Fr}+\mathrm{rF}$ & $\begin{array}{l}\text { Total number of responses that included perceptions of reflectior } \\
\text { A key part of the formula for the Egocentricity Index, when this } \\
\text { sum is : }>0 \text {, indicates some inflation of self-worth. }\end{array}$ \\
\hline Lambda & $\begin{array}{l}\text { Approximates how psychologically available subject is to } \\
\text { engaging in a task with an unfamiliar stimulus. Low lambda shor } \\
\text { that the subject is amenable to involvement in the stimulus; but } t \\
\text { lower the Lambda score the more likey the subject is to becomin } \\
\text { over involved or lost in detail. Conversely, the higher the Lambd } \\
\text { score the greater the tendency to narrow focus, and pay less } \\
\text { attention to detail. }\end{array}$ \\
\hline $\mathrm{R}$ & Total number of responses to all ten inkblots. \\
\hline SUMC' & $\begin{array}{l}\text { Sum of percepts that included achromatic color, which suggests } \\
\text { dysphoria. }\end{array}$ \\
\hline $\mathrm{T}$ & Measure of need for physical intimacy. \\
\hline $\mathrm{V}$ & Measure of negative introspection or self-loathing. \\
\hline WSUM6 & $\begin{array}{l}\text { Determines quality of ideation. A higher score contributes to } \\
\text { evidence of psychotic processes, a very low score suggests } \\
\text { conventionality. }\end{array}$ \\
\hline $\mathrm{X}-\%$ & $\begin{array}{l}\text { Percentage of percepts that either rarely or did not occur in the } \\
\text { norming sample, and are thought to be caused by perceptual } \\
\text { inaccuracy or mediational distortion. }\end{array}$ \\
\hline
\end{tabular}




\begin{tabular}{|c|c|}
\hline Variable & Alphabetized Description of Variables and Constructs \\
\hline $\mathrm{Zd}$ & $\begin{array}{l}\text { Measure of scanning efficiency. The lower the value, the mort } \\
\text { likely the subject is to make hasty assessments of the stimulu } \\
\text { field, and to neglect important pieces of information. } \\
\text { Conversely, higher scores can indicate a tendency to get mire } \\
\text { in detail. }\end{array}$ \\
\hline
\end{tabular}




\section{Appendix B}

Definition of Cluster Interpretation Key Variables Shown in Tables 3 and 4

Adj D is minus: When this index is positive, it suggests that the subject has difficulty with impulse control due either to situational stressors, chronic stress, or insufficient psychological resources.

CDI: Suggests that the subject is particularly susceptible to stress, and will function poorly in environments where there are high expectations placed on him/her.

D $<$ Adj D: Indicates that the subject is experiencing situationally-related, possibly transient stress.

DEPI: This is the depression index. A positive score on this index suggests affective instability.

Extratensive: This key variable indicates that the subject employs emotion in decision making more readily than logic.

Introversive: This key variable indicates that the subject prefers to make decisions based on logic rather than feeling.

Lambda: Indicates that the subject has a tendency to narrow the stimulus field, and process only partial information. May also signal reluctance to engage in the task.

M- > 0: Inconclusive finding, but alerts the examiner to possible idiosyncratic features of the subject's thought processes.

$\mathrm{p}>\mathrm{a}+1$ : Suggests that the subject has a passive coping style.

$\underline{\text { Ref }>0}$ : Suggests that the subject has an inflated sense of self-value.

SCZI: This is the schizophrenia index. Although the RCS often renders false positives for this index, a positive SCZI can point to some difficulties with the subject's perceptual accuracy and clarity of thought. Because of the unreliability of this index, the authors of the RCS (Exner, 1991) caution the examiner to make a thorough assessment of the protocol to find supporting evidence of a diagnosis of schizophrenia. 